\title{
Theoretical Studies of Autoxidation of 2-Alkylidene-1,3- cyclohexadione Leading to Bicyclic-Hemiketal Endoperoxides
}

\author{
Christiane André-Barrès, ${ }^{*},+\neq \bullet$ Yannick Carissan, ${ }^{\S}$ and Béatrice Tuccio" \\ ${ }^{\dagger}$ LSPCMIB, UPS, CNRS, UMR 5068, Université de Toulouse, 118 route de Narbonne, 31062 Toulouse cedex 9, France \\ ${ }^{\ddagger}$ Laboratoire de Synthèse et Physicochimie de Molécules d’Intérêt Biologique, CNRS, UMR 5068, 31062 Toulouse, France

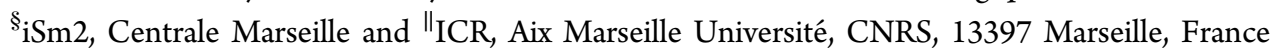

Supporting Information

ABSTRACT: Mechanism of the addition of molecular oxygen on the dienolic form of the 2-alkylidene-1,3-cyclohexadione was investigated by quantum chemical calculations using the approximate projection method developed by Yamaguchi. The complete reaction pathway of the formation of the endoperoxide is described. The crossing between triplet and singlet potential energy surfaces has been located. A multireference complete active space self-consistent field calculation has been performed to strengthen the results.

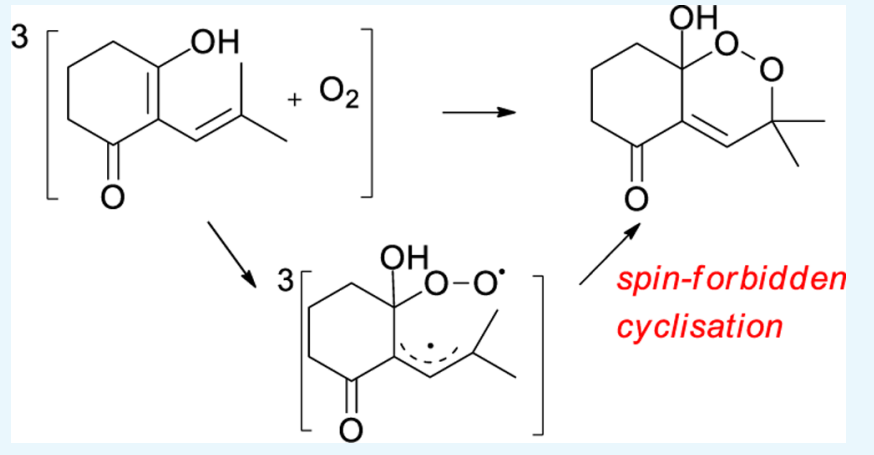

To gain an insight into the mechanism of addition of dioxygen with dienol, a computational approach was employed. The calculations are performed on the simplified 2-alkylidene1,3-cyclohexadione in equilibrium with its ketodienol form, which is also subject to autoxidation (Scheme 2).

The addition of a triplet dioxygen on a singlet dienol will be considered, furnishing a triplet diradical. Because the reactants taken together have a triplet potential energy surface (PES), whereas the endoperoxide product resides on a singlet potential energy surface, a triplet-singlet interconversion must occur at some point along the reaction coordinates. In this way, a change in multiplicity from triplet to open-shell singlet of the obtained diradical is necessary to finally obtain the closed-shell singlet endoperoxide. It is worth noting that the crossing between triplet and singlet potential energy surfaces arises and has to be located. We report herein a density functional theory (DFT) study of the complete pathway leading to bicyclichemiketal endoperoxides.

\section{COMPUTATIONAL METHOD}

Gaussian 09 was used for all of the computations and analytical frequencies were calculated for all of the stationary points. ${ }^{8}$ The energy of the singlet diradical after correction of the spin contamination was provided by the approximate spin projection method developed by Yamaguchi. ${ }^{9}$ The spin-corrected energy value, ${ }^{1} E_{\mathrm{SC}}$, can be obtained as follows

Received: July 13, 2017

Accepted: August 18, 2017

Published: September 1, 2017 
Scheme 1
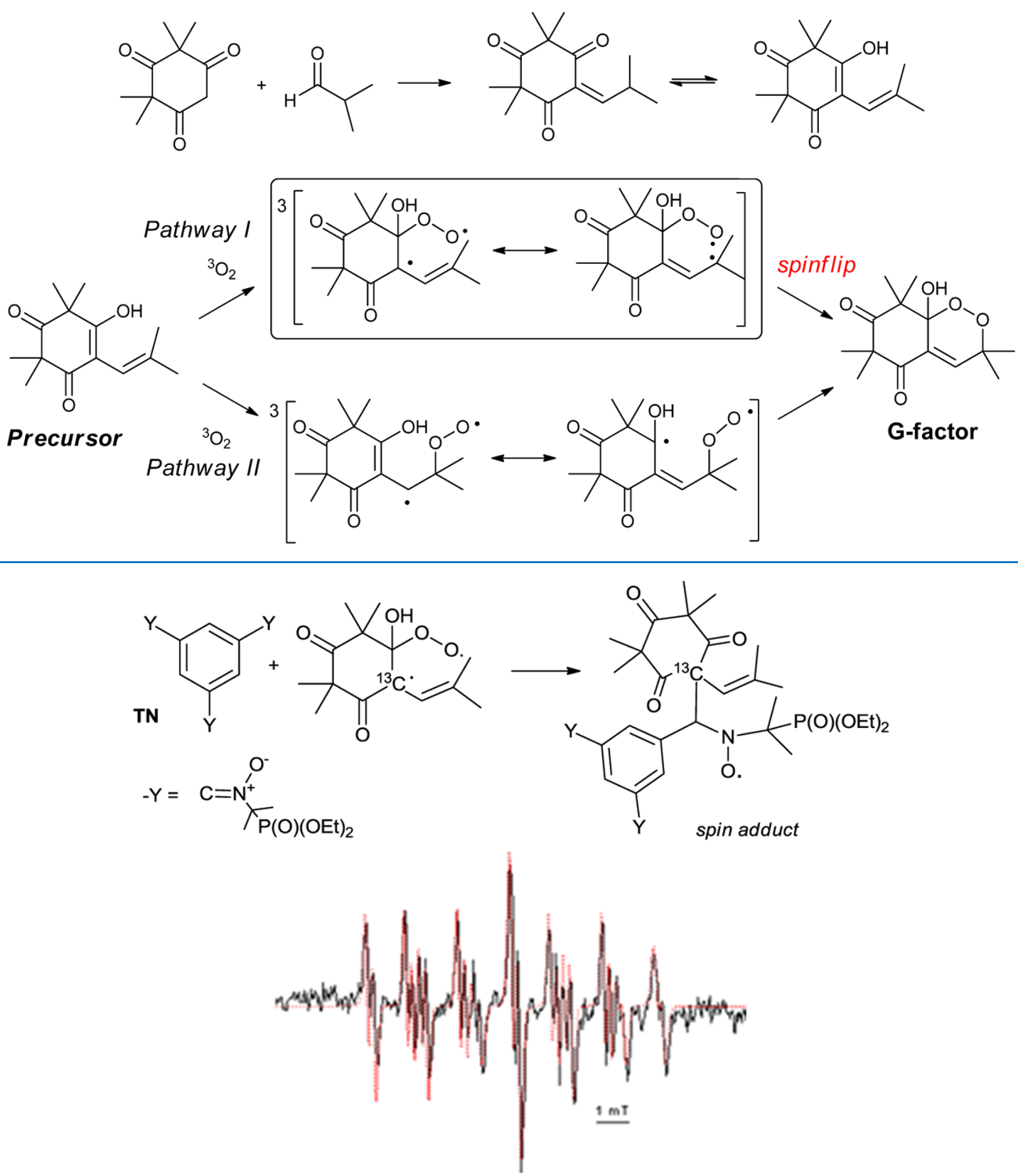

Figure 1. EPR signal obtained in benzene after $1 \mathrm{~h}$ of reaction between molecular oxygen and precursor $\left(0.2 \mathrm{~mol} \mathrm{dm}^{-3}\right)$ in the presence of TN $(80$ $\mathrm{mmol} \mathrm{dm}{ }^{-3}$ ). The superimposed simulation (red dotted lines) led to the following values for the hyperfine coupling constants: $a_{\mathrm{N}}=1.55 \mathrm{mT}, a_{\mathrm{H}}=$ $0.19 \mathrm{mT}, a_{\mathrm{P}}=4.25 \mathrm{mT}$, and $a^{13} \mathrm{C}=1.14 \mathrm{mT}$.

$$
\begin{aligned}
& { }^{1} E_{\mathrm{SC}}={ }^{1} E_{\mathrm{UB}}+f_{\mathrm{sc}}\left({ }^{1} E_{\mathrm{UB}}-{ }^{3} E_{\mathrm{UB}}\right) \\
& \text { with } f_{\mathrm{sc}}={ }^{1}\left\langle S^{2}\right\rangle /\left({ }^{3}\left\langle S^{2}\right\rangle-{ }^{1}\left\langle S^{2}\right\rangle\right)
\end{aligned}
$$

${ }^{1} E_{\mathrm{UB}}$ is the singlet energy computed at the UB3LYP/6$311+\mathrm{G}(\mathrm{d}, \mathrm{p})$ (using "guess $=\mathrm{mix}$ ") and ${ }^{3} E_{\mathrm{UB}}$ is the triplet energy computed at the UB3LYP/6-311+G(d,p).

This method was also applied by Bendikov to describe the Diels-Alder reaction of acenes with singlet and triplet oxygen using the density functional theory. He has shown that B3LYP performs reasonably well for diradicals. ${ }^{10} \mathrm{He}$ used this spinprojected UB3LYP method that revealed to be of interest in modeling triplet and open-shell singlet biradical ground state, and nicely reproduces the singlet-triplet splitting for oxygen.
In addition, recently, Tantillo has used the DFT with Yamaguchi method to study the intramolecular $(2+2)$ cycloaddition reaction, which involves the diradical intermediates from zwitterionic transition state structures. ${ }^{11}$

As a result, we decided to use the DFT calculations with restricted $\mathrm{B} 3 \mathrm{LYP} / 6-311+\mathrm{G}(\mathrm{d}, \mathrm{p})^{12}$ and unrestricted broken symmetry UB3LYP/6-311+G(d,p) levels for all of the closedshell and open-shell species, respectively, to study the spontaneous oxygen uptake on the dienol precursor. ${ }^{13}$ Structures of the singlet diradicals were optimized at the UB3LYP $/ 6-311+G(d, p)$ level with the broken symmetry method (initial guess $\left\langle S^{2}\right\rangle=1$ ) and the structures of the triplet state of diradicals were calculated with the unrestricted method (initial guess $\left\langle S^{2}\right\rangle=2$ ). Spin-projected energies were 
Scheme 2

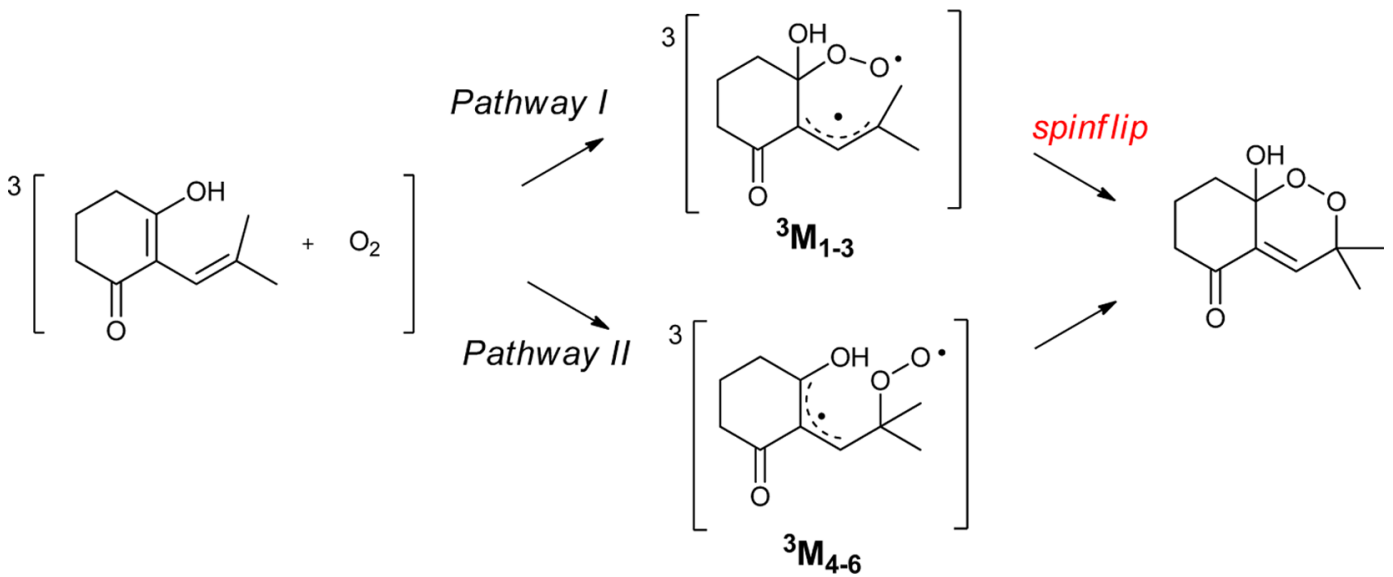

Table 1. Triplet Enthalpies of the Six Minima $M_{1-6}$ and the Singlet Spin-Corrected Enthalpy of $\mathbf{M}_{2}{ }^{a}$

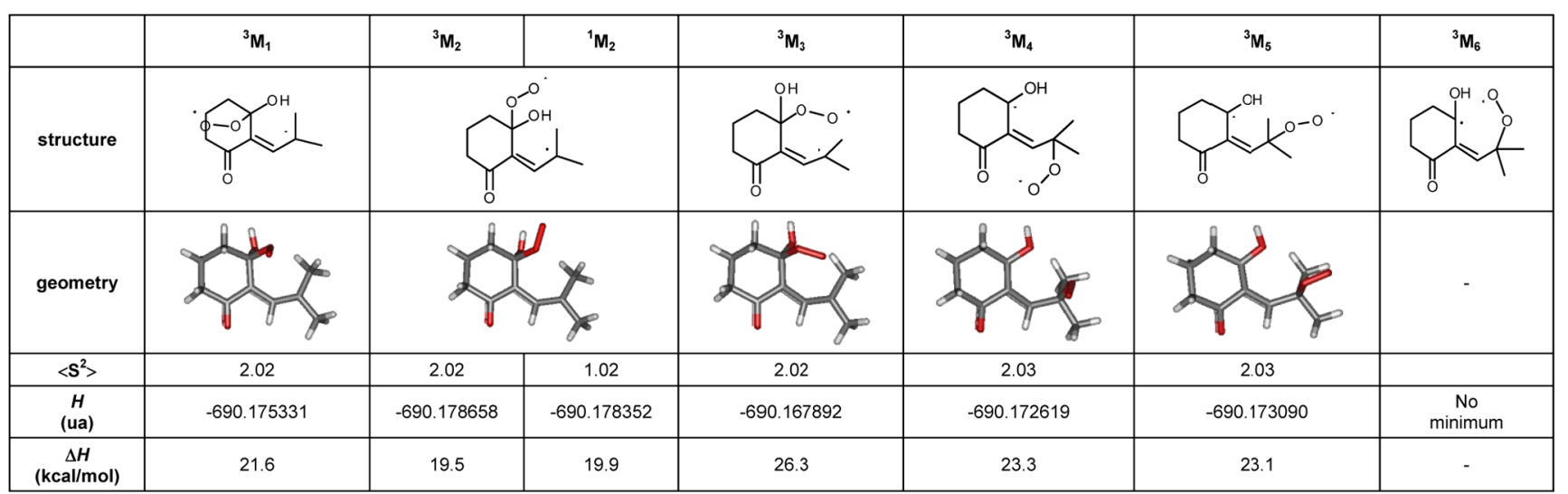

${ }^{a}$ Calculated with the approximate spin-correction procedure proposed by Yamaguchi computed at the UB3LYP 6-311+G(d,p).

Table 2. Triplet Enthalpies of Transition States between ${ }^{3}\left[\right.$ Dienol $\left.+\mathrm{O}_{2}\right]$ and ${ }^{3} \mathrm{M}_{1}$ or ${ }^{3} \mathrm{M}_{2}$, Respectively, Noted ${ }^{3} \mathrm{TS}_{1}$ and ${ }^{3} \mathrm{TS}_{2}$ and Singlet Spin-Corrected Enthalpies of Transition States ${ }^{1} \mathrm{TS}_{2}$ and ${ }^{1} \mathrm{TS}_{\text {form }}$ between, Respectively $\left({ }^{1} \Delta_{\mathrm{g}}-\mathrm{O}_{2}, \mathrm{Dienol}\right)$, and ${ }^{1} \mathrm{M}_{2}$ and ${ }^{1} \mathbf{M}_{2}$ and Endoperoxide

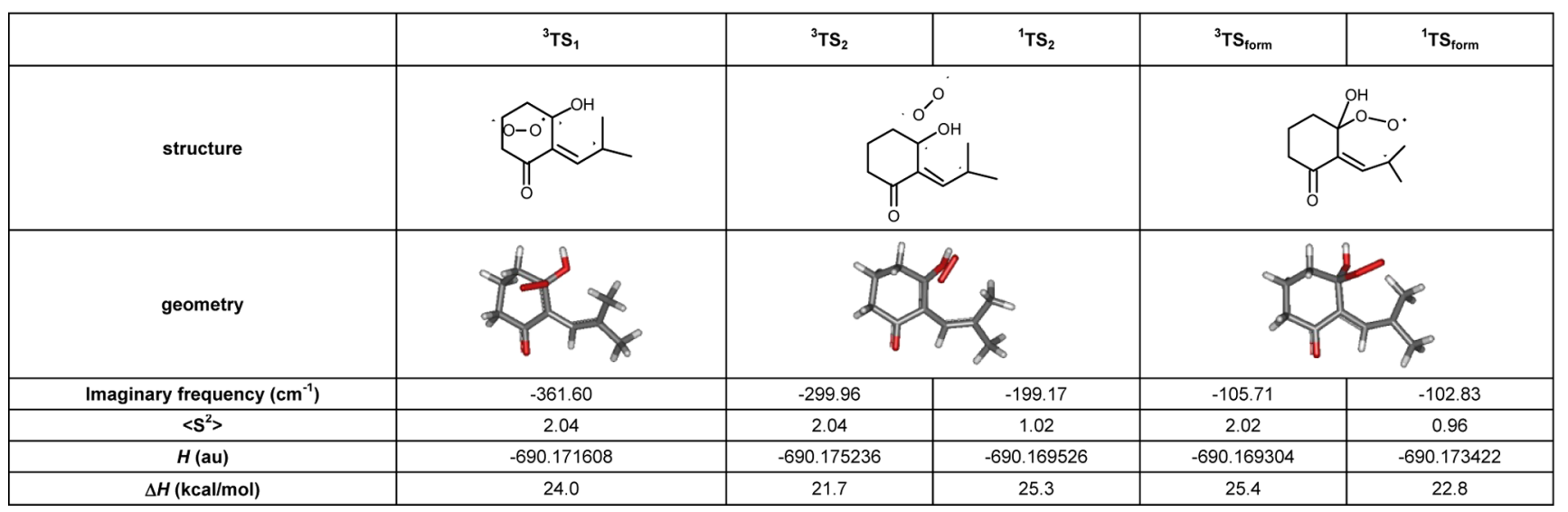

used throughout this paper. To further explore the validity of our results, a multireference complete active space selfconsistent field (CASSCF)(8/8)/6-31G(d) calculation was also performed on some points chosen along the intrinsic reaction coordinate (IRC).

Solvent effects were not investigated, as the autoxidation occurred with or without a solvent.

\section{RESULTS}

The different conformations of the singlet ground state dienol were first calculated (see the Supporting Information) and the lowest one's geometry was retained. The addition of a triplet oxygen ${ }^{3} \Sigma_{\mathrm{g}}^{-}-\mathrm{O}_{2}$ on the dienol can afford three possibilities of geometries in each pathway (A and $\mathrm{B}$ ). Three triplet minima were found for the pathway noted ${ }^{3} \mathrm{M}_{1-3}$ and only two for pathway II noted ${ }^{3} \mathrm{M}_{4}$ and ${ }^{3} \mathrm{M}_{5}$. Despite our efforts, no 


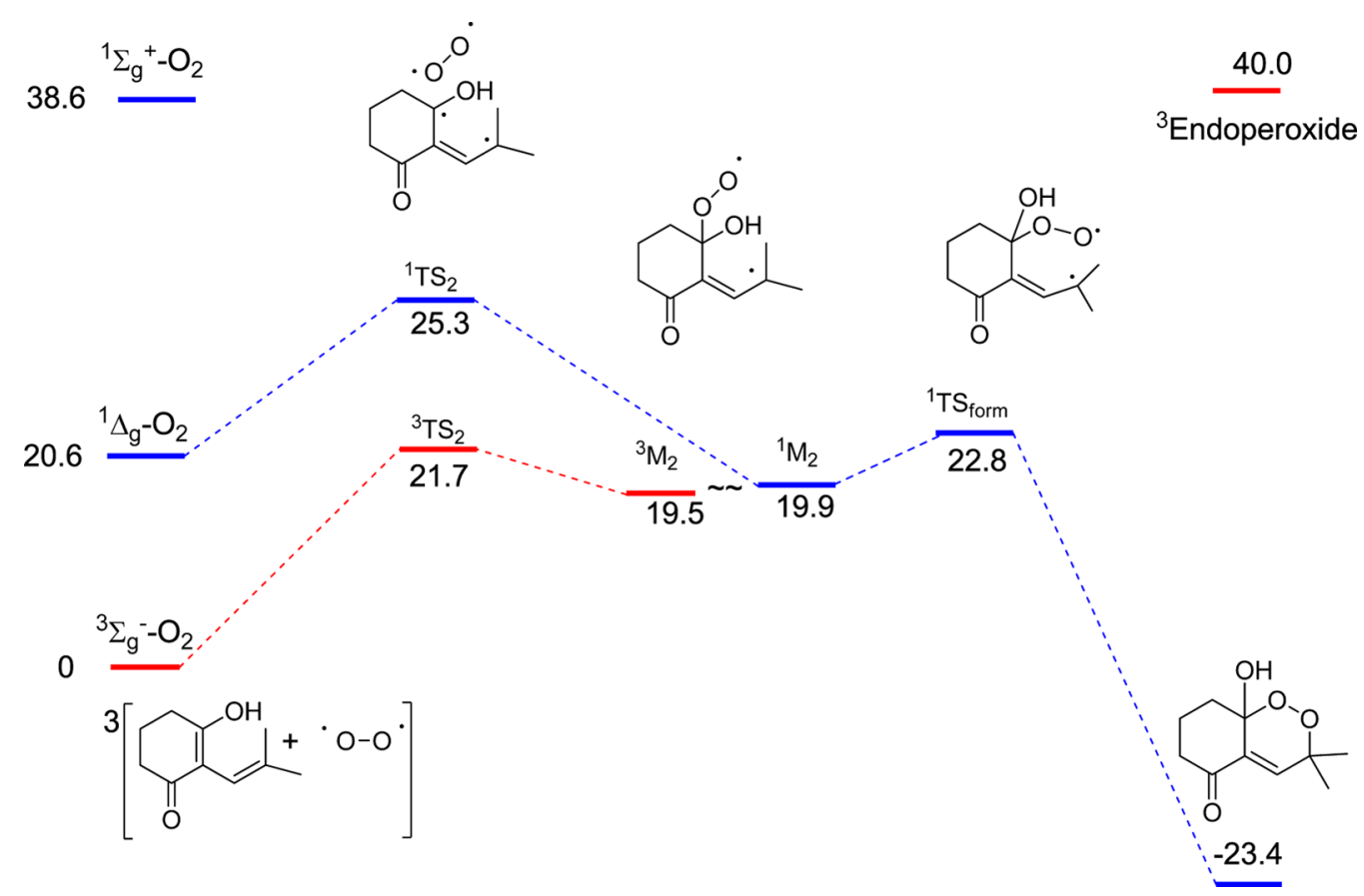

Figure 2. Complete reaction pathway of the autoxidation. Relative enthalpies are in $\mathrm{kcal} / \mathrm{mol}$ at the $(\mathrm{U}) \mathrm{B} 3 \mathrm{LYP} / 6-311+\mathrm{G}(\mathrm{d}, \mathrm{p})$.

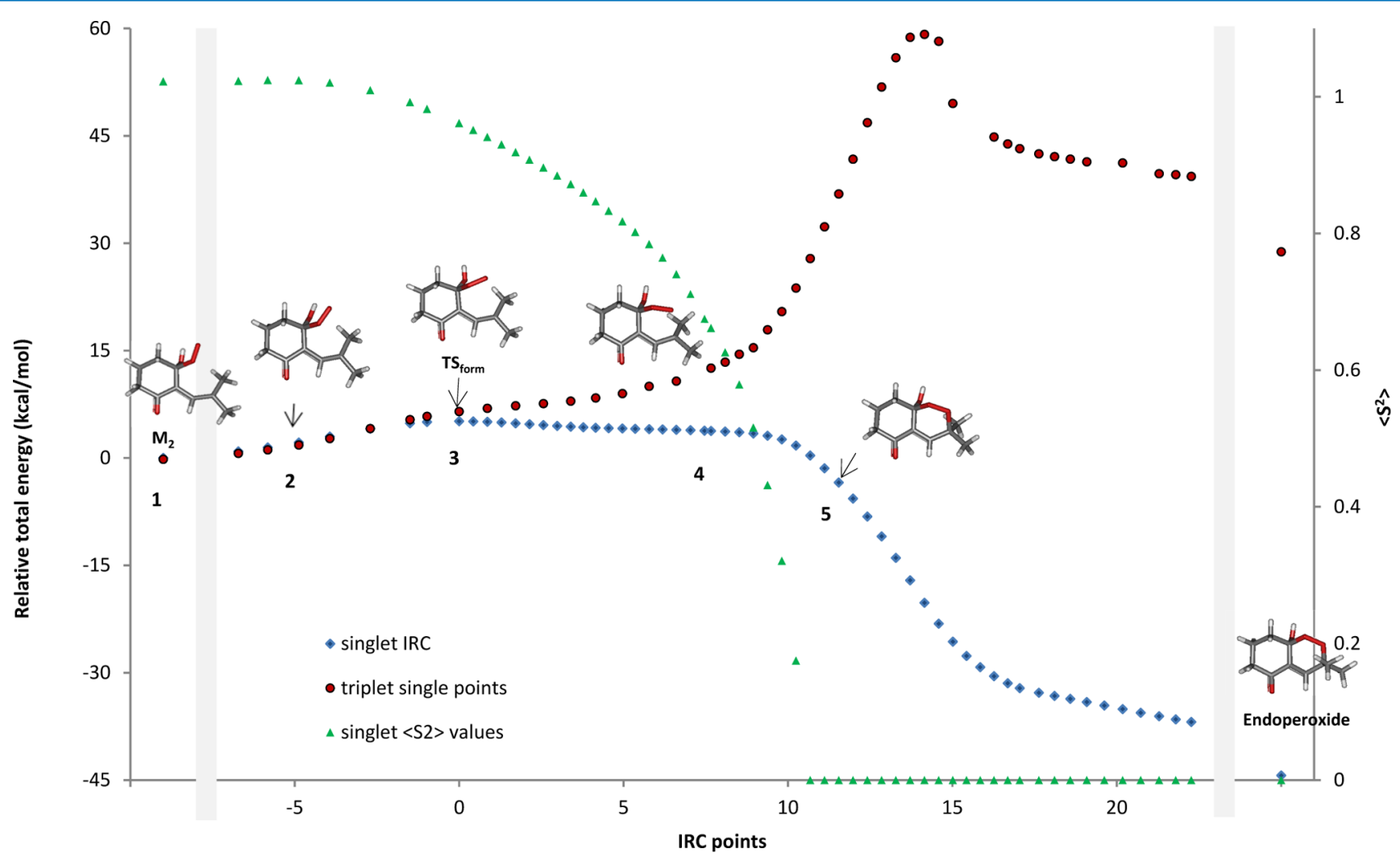

Figure 3. IRC plots connecting the transition state $\mathrm{TS}_{\text {form }}$ to the two minima $\mathrm{M}_{2}$ and the endoperoxide on the singlet potential energy surface $\left({ }^{1} E_{\mathrm{UB}}\right)$. Singlet energies vs reaction coordinate plots are shown in blue, single points triplet energies $\left({ }^{3} E_{\mathrm{UB}}\right)$ in red, and singlet $\left\langle S^{2}\right\rangle$ values vs reaction coordinate plots in green.

minimum could be found for $M_{6}$, for which the initial guess always converged to $\mathrm{M}_{4}$ or $\mathrm{M}_{5}$ geometries. Triplet enthalpies $\mathrm{au})$ and the relative enthalpies $(\mathrm{kcal} / \mathrm{mol})$ with respect to the starting material ${ }^{3}$ (dienol $+\mathrm{O}_{2}$ ) are given in Table 1 .

From all of the minima, ${ }^{3} \mathrm{M}_{2}$, the lowest in energy was located at $19.5 \mathrm{kcal} / \mathrm{mol}$ higher than the ground state of the starting material ${ }^{3}\left(\right.$ dienol $\left.+\mathrm{O}_{2}\right)$. The relative enthalpies for ${ }^{3} \mathrm{M}_{1}$ and ${ }^{3} \mathrm{M}_{3}$ were, respectively, located at 21.6 and $26.3 \mathrm{kcal} / \mathrm{mol}$. This last value is quite high $(7 \mathrm{kcal} / \mathrm{mol}$ higher than that of ${ }^{3} \mathrm{M}_{2}$ ) and could be explained by the destabilizing Pauli repulsion. So, the research of the transition states were first carried on between both ${ }^{3} \mathrm{M}_{1}$ and ${ }^{3}\left(\right.$ dienol $\left.+\mathrm{O}_{2}\right)$ and then ${ }^{3} \mathrm{M}_{2}$ 
Table 3. Occupation Numbers of Orbitals 50-57 of the CASSCF(8,8)/6-31G(d) Calculation on Points $1-5$ in the Singlet and Triplet State and Total Energies $E^{a}$

\begin{tabular}{|c|c|c|c|c|c|c|c|c|c|c|c|}
\hline & & 50 & 51 & 52 & 53 & 54 & 55 & 56 & 57 & $E(\mathrm{au})$ & $\Delta E(\mathrm{kcal} / \mathrm{mol})$ \\
\hline \multirow[t]{2}{*}{1} & singlet & 1.90 & 1.93 & 1.97 & 1.02 & 0.97 & 0.10 & 0.06 & 0.03 & -686.18868 & 0 \\
\hline & triplet & 1.90 & 1.93 & 1.97 & 1.00 & 1.00 & 0.10 & 0.06 & 0.03 & -686.18903 & -0.22 \\
\hline \multirow[t]{2}{*}{2} & singlet & 1.90 & 1.98 & 1.97 & 1.03 & 0.97 & 0.09 & 0.03 & 0.01 & -686.17679 & 7.46 \\
\hline & triplet & 1.91 & 1.98 & 1.97 & 1.00 & 1.00 & 0.09 & 0.01 & 0.03 & -686.17729 & 7.14 \\
\hline \multirow[t]{2}{*}{3} & singlet & 1.91 & 1.98 & 1.97 & 1.21 & 0.79 & 0.09 & 0.01 & 0.03 & -686.17474 & 8.75 \\
\hline & triplet & 1.91 & 1.98 & 1.97 & 1.00 & 1.00 & 0.09 & 0.01 & 0.03 & -686.17247 & 10.72 \\
\hline \multirow[t]{2}{*}{4} & singlet & 1.91 & 1.97 & 1.98 & 1.46 & 0.55 & 0.09 & 0.01 & 0.03 & -686.17763 & 6.93 \\
\hline & triplet & 1.90 & 1.98 & 1.97 & 1.00 & 1.00 & 0.10 & 0.01 & 0.03 & -686.16465 & 15.08 \\
\hline \multirow[t]{2}{*}{5} & singlet & 1.91 & 1.98 & 1.94 & 1.79 & 0.23 & 0.07 & 0.01 & 0.06 & -686.21144 & -14.28 \\
\hline & triplet & 1.94 & 1.97 & 1.02 & 1.90 & 1.00 & 0.09 & 0.01 & 0.06 & -686.15387 & 21.84 \\
\hline
\end{tabular}

and ${ }^{3}\left(\right.$ dienol $\left.+\mathrm{O}_{2}\right)$ and are, respectively, noted ${ }^{3} \mathrm{TS}_{1}$ and ${ }^{3} \mathrm{TS}_{2}$. They were, respectively, found at 24.0 and $21.7 \mathrm{kcal} / \mathrm{mol}$ higher than the ground state (Table 2). These transition states are characterized by only one imaginary frequency at, respectively, -361.6 and $-299.96 \mathrm{~cm}^{-1}$, which are both along the reaction coordinates of the $\mathrm{C}-\mathrm{O}$ bond formation. ${ }^{3} \mathrm{TS}_{2}$ is located below the other minima and below ${ }^{3} \mathrm{TS}_{1}$. As a consequence, the research of other transition states was not further investigated. Using the approximate spin-correction procedure, the enthalpy of the singlet diradical ${ }^{1} \mathrm{M}_{2}$ was found to be very close in energy to the triplet structure (only $0.5 \mathrm{kcal} / \mathrm{mol}$ higher). The singlet ${ }^{1} \mathrm{M}_{2}$ with the same geometry as the triplet ${ }^{3} \mathrm{M}_{2}$ was also a minimum, as its optimized geometry stays unchanged $(\Delta H$ less than $0.01 \mathrm{kcal} / \mathrm{mol}$ ) with no negative frequency. Therefore, singlet and triplet states could be considered as degenerated. The conditions are fulfilled for the intersystem crossing, allowing the possibility that the reaction pathway continues on the singlet potential energy surface, finally leading to endoperoxide. The crossing between triplet and singlet potential energy surfaces will be studied in the area of the reaction pathway (Figure 2).

Futhermore, on the singlet potential energy, we found on the singlet potential energy surface, the transition state ${ }^{1} \mathrm{TS}_{2}$, which relies $\left({ }^{1} \Delta_{\mathrm{g}}-\mathrm{O}_{2}\right.$, dienol) to ${ }^{1} \mathrm{M}_{2}$ with a relative activation enthalpy of $25.3 \mathrm{kcal} / \mathrm{mol}$, a significantly higher barrier than for ${ }^{3} \mathrm{TS}_{2}$ on the triplet surface. This result is in good agreement with the experimental facts in favor of the implication of fundamental oxygen during this autoxidation.

Continuing on the singlet potential energy surface, the transition state $\left({ }^{1} \mathrm{TS}_{\text {form }}\right)$ between ${ }^{1} \mathrm{M}_{2}$ and endoperoxide was located at $22.8 \mathrm{kcal} / \mathrm{mol}$ above the ground state (and lying only $3 \mathrm{kcal} / \mathrm{mol}$ above ${ }^{1} \mathrm{M}_{2}$ ).

An intrinsic reaction coordinates (IRCs) calculation ${ }^{14}$ was performed to connect both the transition state ${ }^{1} \mathrm{TS}_{\text {form }}$ with the endoperoxide in the reverse direction and the minimum ${ }^{1} \mathrm{M}_{2}$ in the forward direction on the singlet potential energy surface. The results are consigned in Figure 3. To characterize the singlet diradical character along the reaction coordinate before the closing of the ring, the $\left\langle S^{2}\right\rangle$ value was reported versus IRC points. The $\left\langle S^{2}\right\rangle$ value of 1.0 in the DFT calculations indicates an equal mixture of singlet $\left(\left\langle S^{2}\right\rangle=0\right)$ and triplet $\left(\left\langle S^{2}\right\rangle=2\right)$. This value of 1 is expected for singlet open-shell diradical structures. At the onset of the closing, the transition state ${ }^{1} \mathrm{TS}_{\text {form }}$ in its singlet state possesses a diradical character with a $\left\langle S^{2}\right\rangle$ value of approximately 1 ; this value then quickly decreases as the peroxide bond is formed. It is worth noting that a singlet PES is very flat as long as $\left\langle S^{2}\right\rangle \neq 0$ and becomes steep as soon as $\left\langle S^{2}\right\rangle=0$. The following reaction consists of the reorganization of all of the structure, leading to endoperoxide, with a $\left\langle S^{2}\right\rangle$ value of 0 , indicating no more diradical character. We have verified that optimization of the last IRC points in both directions converged to endoperoxide in the reverse direction and to $\mathrm{M}_{2}$ in the forward direction.

Single points energy calculations were also performed on the IRC points with an enforced triplet state using UB3LYP/6$311+G(d, p)$, which furnishes the triplet electronic energy versus the reaction coordinates curve. We can observe in Figure 3 the crossing of the triplet and singlet pathways located between $\mathrm{M}_{2}$ and $\mathrm{TS}_{\text {form }}$. To further explore the validity of our results, a multireference calculation at the $\operatorname{CASSCF}(8,8)$ level $^{15}$ was also performed on five chosen geometries on the singlet PES, 1-5, in both singlet and triplet states. The occupation numbers of the eight orbitals of the active space are given in Table 3 for the singlet and the triplet state. In the singlet state, orbitals 53 and 54 are singly occupied for point $1\left(\mathrm{M}_{2}\right)$ to point $3\left(\mathrm{TS}_{\text {form }}\right)$, expressing the open-shell character at the onset of closing, then the occupation number increases for orbital 53 and decreases for orbital 54 (points 4 and 5) until the formation of the $\mathrm{C}-\mathrm{O}$ bond. These results strengthen our previous calculations at the UB3LYP level using Yamaguchi's method. The $\left\langle S^{2}\right\rangle$ value of $\approx 1.0$ (equal mixture of singlet and triplet) found for points 1-3, characterizing singlet open-shell diradical structures, is well correlated with the occupation numbers of orbital 53 and 54. Then $\left\langle S^{2}\right\rangle$ decreases to $0(0.675$ for point 4 and 0 for point 5), characterizing closed-shell structures. Concomitantly, the two electrons fill the orbital 53 and orbital 54 becomes empty, indicating no more diradical character. As can be seen from Figure 4, orbital 53 of point 5 with the occupation number of 1.8 in its singlet state shows the $\mathrm{C}-\mathrm{O}$ bond formation. For the triplet state of point $\mathbf{5}$, the energy of one singly occupied orbital drops below that of a

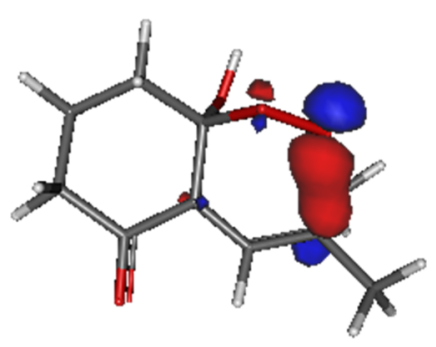

Figure 4. Orbital 53 of the $\operatorname{CASSCF}(8 / 8) / 6-31 G(d)$ calculation for the point 5 in its singlet state with the occupation number 1.8 . 
doubly occupied orbital. Thus, for this point only, orbitals 52 and 54 are singly occupied. Yet, as can be seen from their shapes in the Supporting Information, they do correspond to orbitals 53 and 54 of the four previous points (1-4).

The orbitals 53 (or 52 for the triplet last point) and 54 of the five points $(\mathbf{1 - 5})$ at $\operatorname{CASSCF}(8,8) / 6-31 G(d)$ level both in singlet and triplet state are shown in the Supporting Information.

\section{CONCLUSIONS}

A plausible reaction pathway of the autoxidation of the ketodienol has been investigated by using the unrestricted B3LYP/6-311+G(d,p) level of theory, which appears to perform well for diradicals using the spin-projected Yamaguchi's method and the results have been strengthened by the $\operatorname{CASSCF}(8,8)$ calculations. We theoretically demonstrated that the oxygen uptake occurred between singlet dienol and fundamental triplet dioxygen following pathway I, with an overall barrier reaching $22.8 \mathrm{kcal} / \mathrm{mol}$. The crossing between triplet and singlet PES has been located. This computational study is in good agreement with the experimental reaction conditions and our previous spin trap experiments. The DFT method, low in cost, seems convenient to qualitatively describe the autoxidation.

\section{ASSOCIATED CONTENT}

\section{S Supporting Information}

The Supporting Information is available free of charge on the ACS Publications website at DOI: 10.1021/acsomega.7b00989.

Geometries and electronic energies and enthalpies at the B3LYP/6-311+G(d,p) level of all of the stationary points; orbitals 53 and 54 of the five points $1-5$ chosen on the singlet IRC, at the singlet and triplet states at the $\operatorname{CASSCF}(8,8) / 6-31 G(d)$ level (PDF)

\section{AUTHOR INFORMATION}

\section{Corresponding Author}

*E-mail: candre@chimie.ups-tlse.fr.

\section{ORCID}

Christiane André-Barrès: 0000-0002-8973-1875

\section{Notes}

The authors declare no competing financial interest.

\section{ACKNOWLEDGMENTS}

The CNRS and Universite de Toulouse, UPS (UMR 5068) are gratefully acknowledged for financial support. Frederic Rodriguez is also acknowledged for Gaussian 09 package installation.

\section{REFERENCES}

(1) Ghisalberti, E. Bioactive acylphloroglucinol derivatives from Eucalyptus species. Phytochemistry 1996, 41, 7-22.

(2) Ruiz, J.; Azéma, J.; Payrastre, C.; Baltas, M.; Tuccio, B.; Vial, H.; André-Barrès, C. Antimalarial bicyclic peroxides belonging to the Gfactor family: mechanistic aspects of their formation and iron (II) induced reduction. Curr. Top. Med. Chem. 2014, 14, 1668-1683.

(3) (a) Gavrilan, M.; André-Barrès, C.; Baltas, M.; Tzedakis, T.; Gorrichon, L. Bicyclic peroxides in the $\mathrm{G}$ factors series: synthesis and electrochemical studies. Tetrahedron Lett. 2001, 42, 2465-2468. (b) Najjar, F.; Baltas, M.; Gorrichon, L.; Moreno, Y.; Tzedakis, T.; Vial, H.; André-Barrès, C. Synthesis and electrochemical studies of new antimalarial endoperoxides. Eur. J. Org. Chem. 2003, 2003, 33353343.

(4) (a) Najjar, F.; André-Barrès, C.; Lauricella, R.; Gorrichon, L.; Tuccio, B. EPR/spin trapping study of the spontaneous addition of dioxygen on a dienol. Tetrahedron Lett. 2005, 46, 2117-2119. (b) Bernat, V.; André-Barrès, C.; Baltas, M.; Saffon, N.; Vial, H. Synthesis of antimalarial G-factors endoperoxides: relevant evidence of the formation of a biradical during the autoxidation step. Tetrahedron 2008, 64, 9216-9224. (c) Drujon, J.; Rahmani, R.; Héran, V.; Blanc, R.; Carissan, Y.; Tuccio, B.; Commeiras, L.; Parrain, J.-L. Trans-1,2Disiloxybenzocyclobutene, an adequate partner for the auto-oxidation: EPR/spin trapping and theoretical studies. Phys. Chem. Chem. Phys. 2014, 16, 7513-7520.

(5) Triquigneaux, M.; Charles, L.; André-Barrès, C.; Tuccio, B. A combined spin trapping/EPR/mass spectrometry approach to study endoperoxide formation by dienolic precursor autoxidation. Org. Biomol. Chem. 2010, 8, 1361-1367.

(6) Roubaud, V.; Dozol, H.; Rizzi, C.; Lauricella, R.; Bouteiller, J. C.; Tuccio, B. Poly $(\beta$-phosphorylated nitrones): preparation and characterisation of a new class of spin trap. J. Chem. Soc., Perkin Trans. 2 2002, 2, 958-964.

(7) Bernat, V.; Coste, M.; André-Barrès, C. Autoxidation of 2alkylidene-1,3-cyclohexanediones as a green process to form bicyclic hemiketal endoperoxides. New J. Chem. 2009, 33, 2380-2384.

(8) Frisch, M. J.; Trucks, G. W.; Schlegel, H. B.; Scuseria, G. E.; Robb, M. A.; Cheeseman, J. R.; Scalmani, G.; Barone, V.; Mennucci, B.; Petersson, G. A.; Nakatsuji, H.; Caricato, M.; Li, X.; Hratchian, H. P.; Izmaylov, A. F.; Bloino, J.; Zheng, G.; Sonnenberg, J. L.; Hada, M.; Ehara, M.; Toyota, K.; Fukuda, R.; Hasegawa, J.; Ishida, M.; Nakajima, T.; Honda, Y.; Kitao, O.; Nakai, H.; Vreven, T.; Montgomery, J. A., Jr.; Peralta, J. E.; Ogliaro, F.; Bearpark, M.; Heyd, J. J.; Brothers, E.; Kudin, K. N.; Staroverov, V. N.; Kobayashi, R.; Normand, J.; Raghavachari, K.; Rendell, A.; Burant, J. C.; Iyengar, S. S.; Tomasi, J.; Cossi, M.; Rega, N.; Millam, J. M.; Klene, M.; Knox, J. E.; Cross, J. B.; Bakken, V.; Adamo, C.; Jaramillo, J.; Gomperts, R.; Stratmann, R. E.; Yazyev, O.; Austin, A. J.; Cammi, R.; Pomelli, C.; Ochterski, J. W.; Martin, R. L.; Morokuma, K.; Zakrzewski, V. G.; Voth, G. A.; Salvador, P.; Dannenberg, J. J.; Dapprich, S.; Daniels, A. D.; Farkas, Ö; Foresman, J. B.; Ortiz, J. V.; Cioslowski, J.; Fox, D. J.. Gaussian 09, revision A.1; Gaussian, Inc.: Wallingford, CT, 2009.

(9) Yamaguchi, K.; Jensen, F.; Dorigo, A.; Houk, K. N. A spin correction procedure for unrestricted Hartree-Fock and Møller-Plesset wavefunctions for singlet diradicals and polyradicals. Chem. Phys. Lett. 1988, 149, 537-542.

(10) Ravikumar Reddy, A.; Bendikov, M. Diels-Alder reaction of acenes with singlet and triplet oxygen-theoretical study of two-state reactivity. Chem. Commun. 2006, 1179-1181.

(11) Nguyen, Q. N. N.; Tantillo, D. J. When to let go - diradical intermediates from zwitterionic transition state structures? J. Org. Chem. 2016, 81, 5295-5302.

(12) Hariharan, P. C.; Pople, J. A. The influence of polarization functions on molecular orbital hydrogenation energies. Theor. Chim. Acta 1973, 28, 213-222.

(13) (a) Becke, A. D. Density-functional thermochemistry. III. The role of exact exchange. J. Chem. Phys. 1993, 98, 5648-5652. (b) Lee, C.; Yang, W.; Parr, R. G. Development of the Colle-Salvetti correlation-energy formula into a functional of the electron density. Phys. Rev. B 1988, 37, 785-789.

(14) (a) Hratchian, H. P.; Schlegel, H. B. Accurate reaction paths using a Hessian based predictor-corrector integrator. J. Chem. Phys. 2004, 120, 9918-9924. (b) Hratchian, H. P.; Schlegel, H. B. In Theory and Applications of Computational Chemistry: The First 40 Years; Dykstra, C. E., Frenking, G., Kim, K. S., Scuseria, G., Eds.; Elsevier: Amsterdam, 2005; pp 195-249. (c) Hratchian, H. P.; Schlegel, H. B. Using Hessian Updating To Increase the Efficiency of a Hessian Based Predictor-Corrector Reaction Path Following Method. J. Chem. Theory Comput. 2005, 1, 61-69.

(15) (a) Olsen, J.; Roos, B. O.; Jørgensen, P.; Jørgen, H. J. A. Determinant based configuration interaction algorithms for complete 
and restricted configuration interaction spaces. J. Chem. Phys. 1988, 89,

2185. (b) Cramer, C. Essentials of Computational Chemistry; John

Wiley and Sons, Ltd.: Chichester, 2002; pp 191-232. 